\title{
Na cozinha com Câmara Cascudo: história, etnografia e folclore nos estudos da alimentação no Brasil
}

\author{
Luiz Antonio Oliveira \\ Universidade Federal do Piauí \\ Julie Cavignac \\ Universidade Federal do Rio Grande do Norte
}

Resumo: A partir da trajetória intelectual de Luís da Câmara Cascudo é proposto, neste ensaio, um olhar sobre a formação do campo de estudos da alimentação no Brasil. No diálogo com Mário de Andrade e Gilberto Freyre, Cascudo adota uma abordagem histórica e etnográfica que o faz interessar-se pelas predileções alimentares do povo ou por seu paladar na antecipação de ideias como a de sistema alimentar. Nas pesquisas sobre a comida brasileira constrói sua antropologia nativa à margem do espaço universitário, onde a marginalidade acadêmica de sua obra reflete a marginalidade dos estudos de folclore associados a um projeto de nacionalização considerado ultrapassado.

Palavras-chave: Estudos de alimentação; Folclore; Etnografia histórica; Antropologia nativa; Câmara Cascudo. 


\title{
In the kitchen with Câmara Cascudo: history, ethnography and folklore in food studies in Brazil
}

\begin{abstract}
From the intellectual trajectory of Luís da Câmara Cascudo, in this essay, we propose a look at the field of food studies in Brazil. In the dialogue with Mário de Andrade and Gilberto Freyre, Cascudo adopts a historical and ethnographic approach that makes him interested in the food predilections of the people or his taste in the anticipation of ideas such as the food system. In research on Brazilian food, he builds his native anthropology on the margins of university space, where the academic marginality of his work reflects the marginality of folklore studies associated with a nationalization project considered outdated.

Keywords: Feeding studies, Folklore, Historical ethnography, Native anthropology, Câmara Cascudo.

\section{En la cocina con Câmara Cascudo: historia, etnografía y folclore en los estudios de la alimentación en Brasil}

Resúmen: A partir de la trayectoria intelectual de Luís da Câmara Cascudo se propone, en este ensayo, una mirada sobre el campo de estudios de la alimentación en Brasil. En el diálogo con Mário de Andrade y Gilberto Freyre, Cascudo adopta un enfoque histórico y etnográfico lo que hace interesarse por las predilecciones alimentarias del pueblo o por su paladar en la anticipación de ideas como la de sistema alimentario. En las investigaciones sobre la comida brasileña construye su antropología nativa al margen del espacio universitario, donde la marginalidad académica de su obra refleja la marginalidad de los estudios de folclore asociados a un proyecto de nacionalización considerado superado.

Palabras clave: Estudios de alimentación, Folclore, Etnografía histórica, Antropología nativa, Cámara Cascudo. 


\section{Introdução}

No Nordeste brasileiro, Gilberto Freyre e Luís da Câmara Cascudo destacaram-se pela elaboração de reflexões acerca da cultura e da identidade regionais, legando importantes contribuições para a compreensão histórica das manifestações culturais locais. Precursores do que hoje poderíamos chamar antropologia histórica no Brasil, seus estudos ilustram aspectos pouco valorizados pelas ciências sociais da época. Assim, por exemplo, ao estudar o universo cultural dos engenhos - marcante herança da experiência colonial brasileira - descrevem formas de comportamento e demais expressões culturais, dos ritos à tradição oral, encontradas em todo litoral nordestino. Semelhante à concepção braudeliana de longue durée, os comportamentos populares, na obra histórico-etnográfica de Freyre e Cascudo, unem passado e presente, pondo em evidência a estrutura ou a lógica cultural nativa de uma região. Os pensadores pernambucano e potiguar construíram, desse modo, uma abordagem etnográfica da história que, da casa grande ao sertão, privilegia o cotidiano. Nessa "percepção medular da contemporaneidade", nos dizeres de Cascudo (1968), encontramos as constantes da nossa formação sociocultural.

A alimentação (ou mais exatamente a comida, a refeição, o gosto ou o paladar) figura, aos olhos desses fundadores de uma antropologia na região e da região, como uma dessas constantes informadoras das identidades regional e nacional. Reflexões inovadoras, os escritos de Freyre e Cascudo sobre a alimentação inauguram um campo de investigações no Brasil redescoberto pela academia somente tempos depois 1 . Tema que se faz presente em praticamente toda a obra folclórico-etnográfica e histórica de Câmara Cascudo, a alimentação popular, em sua "normalidade" ou "dias festivos", traduz-se em matéria quase obrigatória do seu interesse investigativo. Além da constância no conjunto dos estudos cascudianos, ganham relevo suas obras devotadas exclusivamente ao tema, como A cozinha africana no Brasil, História da Alimentação no Brasil e Antologia da Alimentação no Brasil, publicadas pela primeira vez, respectivamente, em 1964, 1967/68 e 1977, logo tornadas referência para os pesquisadores do assunto.

Câmara Cascudo destaca-se também no ofício de tradutor dos relatos de viajantes estrangeiros, como Henry Koster e Ermanno Stradelli, que realizaram, em seus depoimentos e estudos, valiosas descrições de hábitos alimentares de

${ }^{1}$ Os primeiros estudos acadêmicos na área das ciências sociais que abordaram o tema da alimentação estão ligados aos chamados estudos de comunidade, realizados, sobretudo, entre as décadas de 40 e 60 , sob forte influência do paradigma funcionalista. É a partir da década de 70 que cresce o interesse pelos aspectos sociais do fenômeno em um contexto cada vez mais urbanizado, principalmente, entre as classes menos favorecidas, oriundas do meio rural. Nessa etapa, marcada pela expansão dos cursos de pós-graduação na área, os estudos se dão sob a influência de novas correntes de pensamento, como o estruturalismo, a fenomenologia, a etnometodologia, as correntes compreensivas, o marxismo etc. Sobre o assunto, ver, dentre outros, os estudos de Canesqui (1988: 2005). 
um Brasil tradicional ou "velho", situado, sobretudo, entre o século XIX e primeiras décadas do seguinte. Tais hábitos, ainda "sobreviventes" em diversas modalidades contemporâneas de expressões culturais populares no mundo rural e urbano, são percebidos pelo mestre potiguar do folclore como alguns dos alicerces sobre os quais se edificou a formação da nacionalidade. Sob esse aspecto, Cascudo reedita as teses clássicas de interpretação sobre o Brasil, insistindo sobre a ideia da mestiçagem como fundamento da identidade nacional. Desse modo, cartografando as contribuições do "cardápio indígena", da "dieta africana" e da "ementa portuguesa" como fontes da cozinha brasileira, apresenta, nos dizeres de Gonçalves (2004), uma interpretação nativa do que pode ser chamado "sistema culinário" popular brasileiro. A síntese das diferentes tradições culinárias, formando esse sistema, teria se dado a partir da "ciência colonizadora do português (...) na transmissão do seu paladar aos aborígenes e sucessores" (Cascudo, 2004: 242).

Sendo assim, até a feijoada, "prato mais gloriosamente nacional do Brasil", é tomada como exemplo dessa mestiçagem levada a cabo dentro de "um modelo aculturativo" português (Cascudo, 2004). Na consideração dos percursos de formação desse modelo alimentar mestiço, Cascudo busca demonstrar, por meio da antiguidade de certas predileções, a "suficiência" do paladar como princípio de análise e norma cultural definidora de diferentes relações sociais. Antecipando o alcance de construções metodológicas empregadas na atualidade no estudo da alimentação, como as idéias de modelo ou sistema alimentar/culinário, Cascudo aponta para a centralidade da categoria paladar na construção de uma história, sociologia ou antropologia da alimentação. Anuncia, nesse sentido, logo no prefácio da História da alimentação no Brasil, a diferença de perspectivas entre sua abordagem, dedicada a realizar uma etnografia do paladar dos "alimentados", e a de Josué de Castro, devotada à análise do problema da fome "dos carecentes" (Cascudo, 2004: 11-12).

Por fim, vale lembrar que Cascudo, em suas investigações a respeito das comidas e bebidas populares, semelhante às obras de outros intelectuais de província ou regionais (Vilhena, 1996), expressa, por intermédio de uma "experimentação nativa", sua identificação profunda com a cultura tradicional local. Tal condição, já apontada como marca de sua identidade existencial e intelectual, refletindo os conflitos que caracterizam o contexto de nascimento das ciências sociais no Brasil, tem estigmatizado seus estudos históricoetnográficos como essencialmente folclóricos (Gonçalves, 2004). No entanto, acreditamos que a proposta de uma história ou antropologia cascudiana, de modo geral, ou da alimentação, em particular, se desenvolve no momento em que os "intelectuais de província", promovendo diálogos entre o folclore, a sociologia e a antropologia, construíram um campo de conhecimentos e forma de abordagem pluridisciplinares.

\section{Folclore, antropologia e história}

A década de 1920, época em que se inicia a carreira intelectual de Câmara Cascudo, é marcada, na história do pensamento social brasileiro, por importantes debates a respeito da problemática nacional. Nesse momento são gestadas tradições intelectuais que irão exercer notada influência na obra daquele que mais tarde será consagrado, nacional e internacionalmente, como um dos principais nomes no estudo do folclore brasileiro. O modernismo 
paulista, representado pela marcante presença de Mário de Andrade na vida e obra de Cascudo, e o movimento regionalista, proposto por Gilberto Freyre em Pernambuco, são dois exemplos dessas "tradições de saber"2 que ajudaram a formar uma antropologia cascudiana. Nesta ainda se faz notar a presença das preocupações folcloristas que caracterizaram os escritos dos teóricos nacionais da segunda metade do século XIX, como aquela que teria Sílvio Romero ao escrever "o primeiro documentário da literatura oral brasileira" (Cascudo, 1985: 17).

Podemos dizer, então, que a obra de Luís da Câmara Cascudo pertence à cena intelectual brasileira do final do século XIX até os anos 1940, período em que se destacam os trabalhos de Gilberto Freyre (1900-1987), Arthur Ramos (1903-1949), José Rodrigues de Carvalho (1867-1935), Euclides da Cunha (1866-1909), Ascenso Ferreira (1895-1965) Sérgio Buarque de Holanda (19021982), Villa Lobos (1887-1959), Guimarães Rosa (1908-1967), Josué de Castro (1908-1973) e Mário de Andrade (1893-1945), este último precursor das pesquisas etnográficas no Brasil. Nestes e em outros autores do período o problema da nacionalidade era buscado, fundamentalmente, em certas tradições locais e expressões culturais populares. É imbuído de vários dos questionamentos levantados pelos pensadores nacionais e estrangeiros do período que Cascudo inicia a construção de sua extensa obra folclóricoetnográfica.

Leitor de diversos autores estrangeiros classicamente dedicados aos estudos do folclore, como Stith Tompson, Archer Taylor, Ralph Boggs, Arnold Van Gennep, André Varagnac, Teófilo Braga, Ermano Stradelli, Saint Yves, dentre outros, Cascudo recebe, logo na fase inicial de sua formação intelectual, grande influência dos incentivos de Henrique Castriciano e de Mário de Andrade, além dos estudos de Sílvio Romero, Gustavo Barroso, Renato Almeida, Monteiro Lobato etc. Assim, o "folclorismo" a que adere nos primeiro anos de sua carreira está ligado ao papel que esses intelectuais desempenharam no despertar de sua atenção para as tradições, os conhecimentos e as crenças do povo expressos nas lendas, canções e costumes. No seu interesse pelos temas populares, é comum encontrar referências às diferentes modalidades de classificação, preparo e consumo de comidas e bebidas, descritas nos provérbios, nas narrativas, festas e diferentes expressões rituais do povo.

Mantendo uma fecunda relação epistolar com vários desses estudiosos, Cascudo não apenas participou dos debates intelectuais de sua época, mas, com o intuito de fazer comparações e reunir informações sobre determinados hábitos e costumes do povo, conseguiu construir uma obra monumental. Na História da Alimentação no Brasil, por exemplo, conta, em prefácio, que uma das primeiras disposições para a sua realização, após aprovação do projeto editorial do livro, adiado por cerca de vinte anos, foi lançar “(...) as primeiras cartas perguntadeiras para Norte, Centro e Sul. Para Europa e África” (Cascudo, 2004: 11-12).

Nesse sentido, acreditamos, conforme sugestões de Cunha (2004, p. 296) a respeito dos arquivos etnográficos e seu duplo, os arquivos pessoais, que eles devem ser entendidos como construções culturais que permitem compreender, de maneira privilegiada, como se produziram certas narrativas profissionais. A obra de Cascudo, então, logo tornada referência nas investigações sobre as diferentes manifestações culturais populares, dentre elas os hábitos

${ }^{2}$ No sentido de Antonio Candido (1959), termo que se refere à continuidade de estilos, temas, formas ou preocupações entre autores e obras. 
alimentares, é construída num incansável intercâmbio de ideias, reunidas por meio de uma enciclopédica capacidade de classificação e comparação.

Por intermédio do contato estabelecido com Mário de Andrade, com quem trocou fecunda correspondência por duas décadas, o mestre potiguar inicia, a partir de 1936, a publicação de artigos na seção da Revista do Arquivo Municipal de São Paulo intitulada Arquivo Etnográfico. Tal convite, ao lado da sua eleição como membro da Société des Americanistes, ainda em 1934, reflete, sob certo aspecto, o seu reconhecimento como etnógrafo, além do papel já desempenhado de folclorista que acompanhará toda a sua trajetória profissional. Sobre este último aspecto, é oportuno lembrar a criação, em 1941, da Sociedade Brasileira de Folclore em Natal, por meio da qual Câmara Cascudo inscrevia seu nome no movimento folclórico então desencadeado em todo o país3. A Sociedade liderada por Cascudo, criada no mesmo ano em que Arthur Ramos funda, no Rio de Janeiro, a Sociedade Brasileira de Antropologia e Etnografia, como lembra Édison Carneiro (1965: 170-171), teve como grande força o intercâmbio internacional mantido pelo folclorista potiguar com pesquisadores da Europa, Estados Unidos, México, Portugal, Argentina e Uruguai 4.

No percurso que remonta ao início da formação intelectual de Cascudo, também assume importância a sua saída da província, em 1918, para estudar medicina, primeiro em Salvador e logo em seguida no Rio de Janeiro, para desistir de tudo na sequência, voltar para Natal e seguir para Recife com o intuito de cursar direito na prestigiosa Faculdade de Direito pernambucana, berço da intelligentsia nordestina desde finais do século XIX. Desse modo, entre 1924 e 1928, período de sua formação acadêmica em Recife, Cascudo "respirou os ares" da instituição que celebrava, ainda nos anos de 1920, a figura de Sílvio Romero como polemista e aglutinador de uma geração de intelectuais que se autoproclamava revolucionária, trazendo para o cenário intelectual brasileiro "um bando de ideias novas" (Schwarcz, 1993).

Semelhante a Romero, precursor no estudo da "ciência social através do folclore" (Cascudo, 1985: 21), Cascudo aposta na descrição das diferentes manifestações culturais do povo como forma de apreensão das verdadeiras expressões de uma identidade "tradicional" brasileira, herdada dos séculos iniciais de nossa formação nacional. Acreditamos que a escolha da dimensão tradicional ou "folclórica" da cultura popular como objeto de reflexão, aspecto que caracteriza, de um modo geral, os estudos dos fundadores de uma antropologia no Nordeste, está também relacionada à condição "provinciana" ou "regional" desses pensadores e suas obras num determinado momento de suas trajetórias profissionais. Assim, a ocorrência da perspectiva folclórica nas regiões periféricas do país apontaria para a formação de diferentes tradições intelectuais entre, de um lado, os "filhos" de um poder econômico e político decadente e, de outro, os "arautos" do progresso e da modernização políticocultural da nação.

Nesse sentido, ganha destaque a proposta de um movimento regionaltradicionalista vindo do Nordeste, liderado por Gilberto Freyre, que contará com o apoio de Câmara Cascudo. A realização do Primeiro Congresso de

\footnotetext{
3 A respeito de sugestivas reflexões sobre o movimento folclórico no contexto de consolidação das ciências sociais no Brasil, ver os estudos de Vilhena (1996; 1997) e Cavalcanti; Vilhena (1990).

4 Sobre o surgimento dessas instituições, não se deve esquecer que nas décadas de 40 e 50, ideologicamente marcadas por um forte discurso nacionalista, há uma preocupação recorrente na institucionalização de sociedades e aparelhos estatais de "proteção" aos estudos de folclore, como atestam a criação da Comissão Nacional de Folclore em 1947 e da Campanha de Defesa do Folclore Brasileiro em 1958.
} 
Regionalistas do Nordeste em Recife no ano de 1926 contou com a participação do estudioso potiguar, ocasião em que o autor de Casa Grande e Senzala supostamente teria lido o seu famoso Manifesto Regionalista, exortando os intelectuais do Nordeste a saírem em defesa das tradições culturais da região, dentre elas as culinárias. Desde 1924, Freyre presidia as reuniões do Centro Regionalista do Recife onde eram discutidas novas formas de pensar o país, buscando por em evidência o papel da região como elemento constitutivo da nação. Além disso, o Nordeste, segundo o grupo de regionalistas, estaria perdendo a consciência de seus valores históricos e de sua importância para o Brasil dada a crescente influência de valores urbano-industriais difundidos a partir do Sudeste (Gouveia, 1983; Oliven, 1986)5.

A procura de uma identidade regional ou do caráter nacional nas expressões culturais tradicionais do povo encontraria eco em alguns dos estudos de redefinição ou redescoberta do Brasil surgidos a partir dos anos de 19306. Situado no interior desse debate, Cascudo inicia, nesse período, a sua produção folclórico-etnográfica. Pode-se tomar como exemplo a publicação, em 1934, de Viajando o Sertão, crônica de uma longa viagem de $1.307 \mathrm{Km}$ empreendida pelo sertão do Rio Grande do Norte, além de Vaqueiros e Cantadores, publicada em 1939, descrevendo importantes aspectos dos costumes sertanejos. O criador de uma antropologia nativa 7 e amante da literatura, em seus estudos sobre as expressões culturais do povo, inclusive as relacionadas às comidas e bebidas, mesclava dados armazenados na sua memória, coligidos nas entrevistas com exescravos, ex-proprietários de escravos, cozinheiras, empregadas domésticas, pescadores etc. com uma erudição de historiador clássico, produzindo uma obra extensa e original.

Seus textos, apesar de inseridos no contexto de discussões que, desde o final do século XIX, estudavam os problemas de formação da unidade nacional ou regional, também celebravam as histórias locais de personagens anônimos e seus feitos. Assim, a tradição, a cultura popular ou o folclore, mais do que o conceito oitocentista de raça, ganha relevo em suas reflexões, pondo em evidência intencionalmente os costumes ou a tradição, verdadeira ciência do povo. No tópico alimentação, comida ou refeição destaca-se a categoria paladar, aglutinadora de sistemas sociais e simbólicos e elemento decisivo na compreensão do "respeito de herança dos mantimentos de tradição" (Cascudo, 2004). O emprego de tal categoria, traduzindo a transformação dos "alimentos" em "comida", está ligado a uma forma de abordagem que privilegia os aspectos simbólico-culturais em detrimento dos biológicos ou "dietéticos". O que lhe interessa, então, é o universo dos padrões, regras e normas alimentares que fundamentam a fé inabalável do povo nos saberes culinários da tradição, elegendo certos sabores como "patrimônio seletivo" familiar, regional ou nacional.

Nesse sentido, opõe a universalidade da fome, como questão da ordem da natureza, à especificidade do paladar, percebendo-o como fenômeno sóciohistórico e cultural. Com efeito, o significado da comida na obra de Cascudo, do

\footnotetext{
5 Freyre acredita que o fim da sociedade patriarcal açucareira, célula original da civilização brasileira, deu início ao processo de desequilíbrio entre as regiões do país, potencializando a degradação socioecológica do Nordeste (Albuquerque Jr., 1999: 98-99).

${ }^{6}$ Datam desse período importantes interpretações acerca do país, como aquela sugerida por Sérgio Buarque de Holanda, em Raízes do Brasil, publicado em 1936; Caio Prado Júnior em Formação do Brasil Contemporâneo, publicado em 1942 e, dentre outros, Gilberto Freyre com Nordeste, em 1937, e Interpretação do Brasil, em 1947.

7 José Reginaldo Santos Gonçalves (2004), apresentando algumas categorias culinárias presentes nos textos de Câmara Cascudo, utilizou o termo para referir-se ao aspecto provinciano da sua obra, entendido como marca principal da identidade existencial e intelectual do folclorista potiguar, reconhecendo nos seus escritos a experimentação característica de um etnógrafo nativo.
} 
ato narrativo às práticas rituais, transcende a simples ação de alimentar-se, realizando a transição da natureza à cultura ou, em termos lévi-straussianos, do "sensível" ao "inteligível", do "cru" ao "cozido". Nessa direção, acrescenta que "De todos os atos naturais, o alimentar-se foi o único que o homem cercou de cerimonial e transformou lentamente em expressão de sociabilidade, ritual político, aparato de alta etiqueta" (Cascudo, 2004: 36). Em seus estudos histórico-etnográficos da alimentação, há ainda a distinção entre a comida, ato informal cotidiano e fragmentário dos indivíduos, e a refeição, ação coletiva ou comunitária marcadamente ritualizada. Conforme sugestões de Gonçalves (2004), a abordagem cascudiana desses termos seria informada, ao menos implicitamente, pela noção de fato social total maussiana, uma vez que seria impossível isolá-los de diferentes sistemas de relações sociais e simbólicas.

Desse modo, o que se destaca nos seus textos é a "função simbólica de fraternidade" da alimentação, também descrita nos relatos de viajantes traduzidos por ele. Alguns desses depoimentos ou crônicas relativos à alimentação foram reunidos, ao lado de outros documentos históricos, artigos de jornais antigos, textos literários e de estudiosos do folclore nacional, num único volume intitulado Antologia da alimentação no Brasil. Vindo à lume em 1977, esta obra, nos dizeres de Cascudo, "completa e fecha" a totalidade de seus estudos sobre a alimentação no Brasil. Dentre os relatos de práticas alimentares coligidos pelo etnógrafo-historiador nesta obra e na monumental História da alimentação no Brasil, destacam-se, dentre outros, os textos de Henry Koster, Saint-Hilaire, Karl von den Steinen, Ermanno Stradelli etc. que retratam diferentes hábitos culinários de um Brasil tradicional ou "velho". Dentre esses costumes, Henry Koster, em relato escrito em 1816, descreve a condição epulária e cordial recepção de um senhor de engenho norte-rio-grandense com o jantar servido na casa grande, a uma hora da madrugada com vários "serviços" salgados e doces (Koster,1978), num claro flagrante de "ostentação de hospitalidade e de fartura" da mesa patriarcal aos visitantes (Freyre, 1997).

Em seus estudos históricos e etnográficos, Cascudo, sem indicar com clareza suas fontes, assume, semelhante a um tipo benjaminiano, a condição de narrador dos feitos passados locais, testemunha dos saberes da história e da tradição. Nesse sentido, o ofício de jornalista, exercido desde 1918, no jornal A Imprensa, fundado por seu pai em 1914, parece ter se constituído em importante referência na construção de seus textos, não "domesticados" pela formatação canônica de uma historiografia moderna. O historiador oficial da cidade e do estado, ligado à elite local, soube utilizar de certa licença poética ou mesmo de "autoridade etnográfica" na elaboração de narrativas históricas que poderiam ser consideradas pouco ortodoxas. No entanto, no contexto intelectual que data de finais do século XIX e primeiras décadas do seguinte, história, literatura e etnografia ou folclore se constituíam, praticamente, num único labor para a nossa intelligentsia ambientada nos Institutos Históricos e Museus do país. Concebido como um representante desse momento intelectual, Cascudo realizaria seus estudos movido, sobretudo, por um interesse diletante, de modo independente e autodidata. Mas, a exemplo do que representa a obra de Alfredo de Carvalho para a historiografia pernambucana, Gustavo Barroso ou Capistrano de Abreu para a brasileira e cearense, a obra de Cascudo ocupa um lugar de destaque "na história" da historiografia potiguar e nordestina.

Movido por um interesse etnográfico em apreender as condições de vida cotidiana de personagens na maioria das vezes anônimos, Cascudo constrói uma modalidade de estudos históricos que se aproximaria da corrente historiográfica 
surgida no âmbito da "revolução" teórico-metodológica promovida pela École des Annales. No Rio Grande do Norte alguns estudiosos seguiram as pistas deixadas pelo "mestre Cascudo" na instituição de uma recorrente tradição de estudos histórico-folclóricos que tomam os hábitos cotidianos do povo, confundidos com os aspectos autobiográficos de seus relatos, como mote para as investigações. Dentre eles, destacam-se Helio Galvão, historiador que publicou memórias e crônicas de costumes locais em obras como Cartas da Praia, Novas Cartas da Praia e Derradeiras Cartas da Praia \& Outras Notas sobre Tibau do Sul, Romanceiro: pesquisa e estudo, e Veríssimo de Melo que seguiu de perto os passos do "mestre Cascudinho" em seus estudos de etnografia e folclore, como, por exemplo, em Superstições de São João, publicada em Natal em 1949, Rondas Infantis Brasileiras, de 1953 e Xarias e Canguleiros, de 19688.

Pensamos que os estudos históricos de Cascudo, tomados em conjunto, podem ser interpretados como exemplos de uma abordagem antropológica da história, tendo em vista o seu recorrente interesse em descrever os costumes do povo, próximos e distantes no tempo e no espaço. Assim, buscando saber da "história de todas as cousas do campo e da cidade (...) que leva ao encantamento do passado" (Cascudo, 1968), construiu uma historiografia que celebra tanto personagens ilustres quanto populares. Ainda que influenciado pelo método “popular e étnico” de Sílvio Romero, Cascudo privilegia a dimensão cultural, aproximando-se mais de uma abordagem andradiana da etnografia e folclore ou mesmo culturalista de Gilberto Freyre. Na comunicação entre essas diferentes influências, como um verdadeiro bricoleur, o estudioso potiguar vai construindo a sua antropologia, pouco adaptada a modelos rígidos de pesquisa e análise. É também dessa perspectiva que deve ser considerado o conjunto de suas obras históricas, percebidas, algumas vezes, apenas como exemplos de estudos autodidatas que subvertem certas normas metodológicas "sacralizadas".

As experimentações nativas do etnógrafo provinciano, identificando-o profundamente com o universo pesquisado, fazem com que ele escreva não "sobre a", mas "a partir da" própria cultura popular, observando os costumes tradicionais do Brasil do ponto de vista de suas experiências de província (Gonçalves, 2004). Assim, descrevendo a realidade local e retratando a vida do povo, Cascudo construía a sua antropologia nativa no momento em que se esboçavam experiências pioneiras de uma etnografia sistemática no Brasil. Nesse sentido, vale lembrar que, no Nordeste, é apenas na década de 50 que se inicia a institucionalização das ciências sociais com a criação do Instituto Joaquim Nabuco de Pesquisas Sociais por Gilberto Freyre, momento ainda de franca expansão dos estudos de folclore na região. No período, Cascudo publica as principais de suas obras folclóricas, como o prestigiado Dicionário do Folclore Brasileiro em 1954, Anúbis e outros ensaios e Meleagro, ambos de 1951, Cinco Livros do Povo em 1953, Literatura Oral em 1952, Jangada em 1957, Rede de Dormir em 1959, dentre outros.

É criada também, no final da década de 50, a Universidade no Rio Grande do Norte, local em que irá se institucionalizar, a partir dos anos de 1960, os estudos de antropologia, então identificados com a etnografia e o folclore. No entanto, mais ambientado no espaço do Instituto Histórico e Geográfico do Rio Grande do Norte, fundado por um grupo de intelectuais ligados à elite local em 1902, Cascudo empreende aí vários de seus estudos históricos e etnográficos,

8 Tanto Hélio Galvão quanto Veríssimo de Melo tinham a mesma formação acadêmica de Cascudo, sugerindo a existência de um modelo de trajeto intelectual seguido pelos mestres do folclore na região. Ainda na década de 5o, época áurea do movimento folclórico, Veríssimo de Melo publica, dentre outros, Jogos Populares do Brasil em Portugal, O cavalo no adagiário brasileiro na Espanha e Três aspectos da superstição brasileira na Itália. 
sendo reconhecido por eles como principal estudioso da cultura do povo e historiador oficial do estado e da cidade do Natal9. Seus estudos de etnografia da cultura popular são construídos, então, numa situação de marginalidade acadêmica, relegando-o a uma condição "literária" e não científica. Nesse sentido, vale lembrar a emergência das discussões a respeito da "questão científica" dos estudos de folclore, na década de 1950, período que antecede o momento de reprodução social dos antropólogos no Brasil, como exemplo de sua situação marginal no nascente mundo acadêmico das Ciências Sociais brasileiras (Cavalcanti; Vilhena, 1990).

\section{Considerações finais}

Identificados com a "cultura do povo", porém ligados às estruturas oligárquicas de poder em franco declínio, os intelectuais de província, a exemplo de Cascudo, transitavam entre o mundo da cultura popular e das elites, construindo uma obra de feições ao mesmo tempo popular e erudita. De um modo geral, podemos dizer que, sem pensar a contradição presente, tais intelectuais projetavam funcionalmente no passado as relações entre "as sobrevivências" culturais do povo (as expressões folclóricas atuais) e as antigas formas de poder a que eles estavam associados. É desse modo que, por exemplo, certos elementos simbólicos ligados a uma estrutura patriarcal de poder são consagrados por eles como as verdadeiras bases de nossa identidade.

Agitador cultural da cena intelectual local em constante contato com estudiosos brasileiros e estrangeiros, Cascudo constrói, por meio de seus estudos folclórico-etnográficos e históricos, o que chamamos de uma antropologia nativa. Tal antropologia, praticada por um "provinciano incurável", teria, certamente, algumas particularidades ligadas ao perfil intelectual de seu fundador. Desse modo, ao mesmo tempo orientada por perspectivas teóricas que remontam aos pensadores do final do século XIX e influenciada pelas inquietações e questionamentos regionalistas e modernistas de seu tempo, a proposta de uma antropologia cascudiana apresenta-se de forma complexa e multifacetada. Com uma produção bibliográfica que ultrapassa os 160 livros, além de textos inéditos, o estudioso potiguar nos lega uma importante contribuição para as pesquisas sobre as diferentes expressões culturais do povo - com destaque para a alimentação - como símbolos de uma identidade cultural "tradicional" brasileira.

"Vigilante na pergunta e registro" das tradições alimentares do povo, distanciadas no tempo e no espaço, Cascudo, a exemplo de Gilberto Freyre, propõe uma abordagem inovadora para um campo de investigações ainda pouco explorado no Brasil. Privilegiando "o cotidiano e não o excepcional" na construção de uma história e etnografia nativas da alimentação, o mestre potiguar do folclore, de forma pioneira, chama a atenção para aspectos que os cientistas sociais só recentemente descobriram o seu interesse. Assim, observamos, por exemplo, que a sua obra histórica se aproxima do discurso da História Nova, ao descrever a vida nos engenhos coloniais e antigos costumes do sertão, dando destaque a figuras populares, além de interessar-se pela tradução

9 Cascudo recebe do governador do estado, Sylvio Piza Pedroza, em 1948, o título honorífico de "historiador da cidade do Natal" pela sua obra a respeito da história da cidade, publicada no ano anterior e patrocinada pela prefeitura. Em 1955 escreve História do Rio Grande do Norte, outro estudo histórico de vulto, logo tornado referência nas pesquisas sobre a história do Estado 
dos relatos dos viajantes estrangeiros que se constituem em importantes documentos etnográficos do período.

Ao tomar a categoria paladar como princípio de interpretação em sua etnografia das predileções alimentares do povo, interpretadas como escolhas culturais movidas por ditames sociais e simbólicos, Cascudo aproxima os seus estudos das abordagens contemporâneas sobre o assunto. Desse modo, alicerçada no paladar, portanto, entendida em sua acepção simbólico-cultural, a comida distingue-se da fome que é associada ao aspecto "natural" e não "cultural” da alimentação. Em suas reflexões a respeito de uma culinária ou cozinha brasileira, demonstrando, em alguns momentos, a consagração do produto nativo pela técnica portuguesa, lembra a mestiçagem da tradição culinária do Brasil, explicada pela nossa experiência histórica colonial. Assim, numa perspectiva de interpretação tornada clássica sobre o país, Cascudo propõe como objetivo, na História da alimentação no Brasil, mapear, no passadio popular, as heranças ou contribuições culinárias das três matrizes étnicas que teriam formado a sociedade brasileira.

\section{Bibliografia}

ALBUQUERQUE Jr., Durval Muniz de. A invenção do Nordeste e outras artes. Recife: FJN, Ed. Massangana; São Paulo: Cortez. 1999.

CANDIDO, Antonio. Formação da Literatura Brasileira. São Paulo: Livraria Martins Editora, 1959. vol. I.

CANESQUI, Ana Maria. Antropologia e alimentação. Revista de Saúde Pública. 22(3), p. 207-216, 1998.

CANESQUI, Ana Maria. Comentários sobre os estudos antropológicos da alimentação. In: CANESQUI, Ana Maria; GARCIA, Rosa Wanda Diez (org.). Antropologia e nutrição: um diálogo possível. Rio de Janeiro: FIOCRUZ, 2005. (Coleção Antropologia e Saúde).

CARNEIRO, Édison. Dinâmica do folclore. Rio de Janeiro: Civilização Brasileira, 1965.

CASCUDO, Luis da Câmara. Um provinciano incurável. Província. Natal, IHGRN, nº 2, p. 5-6, 1968.

CASCUDO, Luís da Câmara (Org.). Antologia da alimentação no Brasil. Rio de Janeiro: Livros Científicos Técnicos, 1977.

CASCUDO, Luís da Câmara. Introdução. In: ROMERO, Sílvio. Cantos populares do Brasil. Belo Horizonte: Itatiaia; São Paulo: Ed. Universidade de São Paulo, 1985.

CASCUDO, Luís da Câmara. História da alimentação no Brasil. 3 ed. São Paulo: Global, 2004. 
ACENO, Vol. 4, N. 7, p. 225-236. Jan. a Jul. de 2017.

Cultura Popular, Patrimônio e Performance (Dossiê).

CAVALCANTI, Maria Laura Viveiros de Castro; VILHENA, Luís Rodolfo. Traçando Fronteiras: Florestan Fernandes e a Marginalizaçao do Folclore. Estudos Históricos, 3(5), p. 75-92, 1990.

CAVIGNAC, Julie A.; OLIVEIRA, Luiz Antônio de. A Antropologia nativa de um "provinciano incurável": Câmara Cascudo e os estudos da cultura no Rio Grande do Norte. Trabalho apresentado na 26 ${ }^{\mathrm{a}}$ Reunião Brasileira de Antropologia (01 a 04 jun. 2008, Porto Seguro, Bahia, Brasil), 2008.

CUNHA, Olívia Maria Gomes da. Tempo imperfeito: uma etnografia do arquivo. Mana, 10(02), p. 287-322, 2004.

DUTRA, Rogéria Campos de Almeida. Cozinha e Identidade Nacional: notas sobre a culinária na formação da cultura brasileira segundo Gilberto Freyre e Luís da Câmara Cascudo. Anais do Seminário Gastronomia em Gilberto Freyre, 2005 .

FREYRE, Gilberto. Casa-Grande \& Senzala: formação da família brasileira sob o regime da economia patriarcal. 32 ed. Rio de Janeiro: Record. 1997.

GONÇALVES, José Reginaldo Santos. A fome e o paladar: a antropologia nativa de Luís da Câmara Cascudo. Estudos Históricos, n. 33, 2004.

GOUVEIA, Marielza Campozana. A Antropologia no Nordeste do Brasil. Top. Educ. UFPE 1(3), p. 285-306, 1983.

KOSTER, Henry. Viagens ao Nordeste do Brasil. 2 ed. Recife: Governo do Estado de Pernambuco; Secretaria de Educação e Cultura, 1978. (Coleção Pernambucana, v.XVII).

LÉVI-STRAUSS, Claude. O cru e o cozido. São Paulo: Cosac \& Naif, 2004.

OLIVEN, Ruben George. O nacional e o regional na construção da identidade brasileira. Revista Brasileira de Ciências Sociais, São Paulo, v. 2, p. 68-74, 1986.

Disponível

em:

http://www.anpocs.org.br/portal/publicacoes/rbcs_00_02/rbcs02_07.htm.

SCHWARCZ, Lilia Moritz. O espetáculo das raças: cientistas, instituições e questão racial no Brasil 1870-1930. São Paulo: Companhia das Letras, 1993.

VILHENA, Luís Rodolfo. Os intelectuais regionais: o folclore e o campo das ciências sociais nos anos 50, Revista Brasileira de Ciências Sociais, 11 (32), p. 125-150, 1996.

VILHENA, Luís Rodolfo. Projeto e Missão. O Movimento Folclórico Brasileiro, 1947-1964. Rio de Janeiro: Funarte/Fundação Getúlio Vargas, 1997.

Recebido em 10/06/2017. Aprovado em 26/06/2017. 